\title{
Mechanism by which Bile Salt Disrupts the Gastric Mucosal Barrier in the Dog
}

\author{
William C. Duane and Dorothy M. Wiegand, Department of Medicine, \\ Veterans Administration Medical Center and University of Minnesota, \\ Minneapolis, Minnesota 55417
}

\begin{abstract}
A B S T R A C T Bile salts disrupt a functional "gastric mucosal barrier" increasing net forward-diffusion $(+)$ of $\mathrm{Na}^{+}$and back-diffusion (-) of $\mathrm{H}^{+}$. Studying canine Heidenhain pouches, we attempted to distinguish between two possible mechanisms for this effect: $(a) \mathrm{mu}$ cosal uptake of bile salt with subsequent cellular injury or $(b)$ dissolution of mucosal lipids by intralumenal bile salt. A $10 \mathrm{mM}$ mixture of six conjugated bile salts simulating the proportions found in human bile induced net $\mathrm{Na}^{+}$flux of $15.5 \pm 3.2$ and net $\mathrm{H}^{+}$flux of $-9.9 \pm 3.3$ $\mu \mathrm{eq} / \mathrm{min}$. This change was accompanied by an increase in phospholipid efflux out of gastric mucosa from a base-line value of $13.2 \pm 2.7$ to $54.8 \pm 2.8 \mathrm{nmol} / \mathrm{min}$ $(P<0.001)$ and an increase in cholesterol efflux from $11.7 \pm 3.8$ to $36.3 \pm 3.2 \mathrm{nmol} / \mathrm{min}\left(P^{\circ}<0.001\right)$. Saturation with lecithin $(25 \mathrm{mM})$ and cholesterol $(50 \mathrm{mM})$ blocked disruption of the gastric mucosal barrier by bile salt $\left(\mathrm{Na}^{+}\right.$flux $-1.2 \pm 0.9, \mathrm{H}^{+}$flux $\left.0.6 \pm 1.8 \mu \mathrm{eq} / \mathrm{min}\right)$. A $10 \mathrm{mM}$ solution of taurodehydrocholate, a bile salt that does not form micelles, induced no net $\mathrm{Na}^{+}(-0.3 \pm 0.8)$ or $\mathrm{H}^{+}$ flux $(-0.7 \pm 1.4)$ and did not increase efflux of phospholipid $(11.3 \pm 1.7)$ or cholesterol $(10.4 \pm 2.0)$ over base line. Bile salt was absorbed from the mixture of six conjugates at $752 \pm 85 \mathrm{nmol} / \mathrm{min}$. Addition of subsaturation amounts of lecithin $(4 \mathrm{mM})$ reduced bile salt absorption threefold to $252 \pm 57 \quad(P<0.001)$, but abnormal $\mathrm{Na}^{+}$flux $(14.1 \pm 3.4)$ and $\mathrm{H}^{+}$flux $(-15.6 \pm 3.5)$ persisted. Taurodehydrocholate was absorbed to an intermediate extent $(467 \pm 116)$. Dissolution of mucosal lipids is apparently the mechanism by which bile salt disrupts the gastric mucosal barrier, and presumably at least one mechanism by which bile salt can injure the gastric mucosa.
\end{abstract}

This work was presented in part at the annual meeting of the American Gastroenterological Association, May 19-21, 1980 , in Salt Lake City, Utah.

Received for publication 24 March 1980. and in revised form 15 July 1980.

\section{INTRODUCTION}

Bile salts disrupt a "gastric mucosal barrier" that normally serves to impede movement of $\mathrm{H}^{+}$from lumen into mucosa $(1,2)$. This barrier is not well defined anatomically although it may correspond to the apical plasma membrane of the gastric mucosa (3). Out of necessity, therefore, the barrier is defined in functional terms, and disruption of the barrier is said to have occurred when there is an increase in net flux of $\mathrm{H}^{+}$ out of the gastric lumen into the mucosa (back-diffusion), usually accompanied by net flux of $\mathrm{Na}^{+}$into the lumen. This increased $\mathrm{H}^{+}$back-diffusion can cause tissue injury ranging in animal models from gastritis to frank ulceration (4-7). In man these events may contribute to development of the gastritis that accompanies reflux of bile salt into the stomach after surgical interruption of the pyloric sphincter $(8-10)$.

The mechanism by which bile salts disrupt the gastric mucosal barrier is unknown. One possibility is that bile salt enters the mucosa, subsequently causing cellular injury. In support of this idea Davenport (11) has shown that taurocholate is absorbed from canine gastric pouches. However, there apparently has been no attempt to directly correlate this uptake with disruption of the mucosal barrier. A second possibility is that gastric mucosal damage is mediated through the detergent action of intralumenal bile salt. Two major constituents of mucosal membranes are phospholipid and cholesterol, which are both readily dissolved by bile salt micelles (12). If such dissolution occurred, it would not be surprising to see an associated change in $\mathrm{H}^{+}$ and $\mathrm{Na}^{+}$permeability. Indeed, Slota and Ammon (13) have provided evidence that dissolution of mucosal cholesterol is responsible for alteration of jejunal water transport by bile salt. This study is an effort to distinguish between these two potential mechanisms for disruption of the gastric mucosal barrier: mucosal uptake of bile salt vs. dissolution of mucosal lipids by intralumenal bile salt micelles. 


\section{METHODS}

Sodium salts of conjugated bile acids were purchased (Calbiochem-Behring Corp., American Hoechst Corp., San Diego, Calif.) and used without additional purification. Thin-layer chromatography of $100 \mu \mathrm{g}$ of each of these bile salts on silica gel $G$ in a solvent system of butanol/acetic acid/water, 10:1:1 revealed a single band visualized with sulfuric acid charring. A chromatographic preparation of egg lecithin was obtained commercially (Sigma Chemical Co., St. Louis, Mo.) and shown to be pure by two-dimensional thin-layer chromatography (see below). Small quantities of phosphatidyl ethanolamine, phosphatidyl serine, phosphatidyl inositol, and cardiolipin for use as reference standards were also obtained from Sigma Chemical Co. Cholesterol was purchased (Eastman Kodak Co., Rochester, N. Y.) and shown to be without discernible impurity by thin-layer chromatography using ethyl ether/ heptane, 55:45 as the moving phase.

Radiolabeled taurodehydrocholate was synthesized from $\left[{ }^{14} \mathrm{C}\right]$ taurocholate (New England Nuclear, Boston, Mass.) by oxidation with a mixture of chromic and sulfuric acids dissolved in acetic acid. The final product was purified by preparative thin-layer chromatography on silica gel $\mathrm{G}$ developed in $\mathrm{CHCl}_{3} / \mathrm{MeOH} / \mathrm{HAc} / \mathrm{H}_{2} \mathrm{O}, 65: 20: 10: 5$.

A mixture of six conjugated bile acids simulating the proportions found in human bile was prepared in $0.10 \mathrm{M} \mathrm{NaCl}-$ $0.05 \mathrm{M} \mathrm{PO}_{4}$ buffer ( $\mathrm{pH} 7$ ). This mixture contained $14 \%$ taurocholate, $14 \%$ taurochenodeoxycholate, $5.3 \%$ taurodeoxycholate, $28 \%$ glycocholate, $28 \%$ glycochenodeoxycholate, and $10.7 \%$ glycodeoxycholate. The effect of this mixture with and without added lipids on $\mathrm{Na}^{+}$and $\mathrm{H}^{+}$fluxes was assessed on two separate occasions in each of four Heidenhain pouches using the method of Davenport (1) as described (14). Briefly, pouches were thoroughly washed with a test solution of 100 $\mathrm{mM} \mathrm{HCl}, 45 \mathrm{mM} \mathrm{NaCl}$, and $1 \%$ polyethylene glycol (PEG) ${ }^{1}$ labeled with ${ }^{14} \mathrm{C} .20 \mathrm{ml}$ of this solution was then left in each pouch for $20 \mathrm{~min}$. Contents of the pouches were then removed quantitatively and saved for analysis. This procedure was repeated to provide duplicate base-line estimates of ion fluxes. Pouches were then thoroughly washed with the bile acid solution being tested, which also contained 1\% PEG labeled with ${ }^{3} \mathrm{H} .20 \mathrm{ml}$ of that solution was left in the pouch for $40 \mathrm{~min}$. The pouches were evacuated and quickly washed three times with the $\mathrm{HCl}-\mathrm{NaCl}$ test solution, after which $20 \mathrm{ml}$ of the test solution was left in the pouches for 20 min to determine $\mathrm{Na}^{+}$ and $\mathrm{H}^{+}$net fluxes. In early experiments two such measurements of ion fluxes were performed after removing the bile acid solution; however, the second determination consistently demonstrated partial return of gastric mucosal permeabilities toward base line. Therefore only a single measurement was subsequently used. Test solutions removed from the pouches were assayed in triplicate for $\mathrm{Na}^{+}$by atomic absorption spectrophotometry using a model 303 instrument from PerkinElmer Corp., (Instrument Div., Norwalk, Conn.). Hydrogen ion concentrations were determined in triplicate by titration with $0.100 \mathrm{~N} \mathrm{NaOH}$ using a Radiometer automatic titrator (Radiometer Co., Copenhagen, Denmark).

Net flux of $\mathrm{Na}^{+}$(microequivalents per minute) was calculated for the two pre- and the one postbile acid solution periods according to the following formula:

$$
\text { Net flux }=\frac{\left[\mathrm{Na}^{+}\right]_{0} \mathrm{~V}_{0}-\left[\mathrm{Na}^{+}\right]_{\mathrm{i}} \mathrm{V}_{\mathrm{i}}}{\mathrm{t}}
$$

\footnotetext{
${ }^{1}$ Abbreviations used in this paper: CMC, critical micellar concentration; PEG, polyethylene glycol.
}

where $\left[\mathrm{Na}^{+}\right]_{\mathrm{i}}$ and $\mathrm{V}_{1}$ are concentration of $\mathrm{Na}^{+}$and volume of test solution instilled into the pouch, and $\left[\mathrm{Na}^{+}\right]_{0}$ and $\mathrm{V}_{0}$ are the concentration of $\mathrm{Na}^{+}$and volume of test solution removed from the pouch after time, $t$. In early experiments $V_{0}$ was determined in two ways: by direct measurement of volume removed from the pouch, and by dilution of $\left[{ }^{14} \mathrm{C}\right] P E G$ in the instilled test solution. In the first 40 such double determinations, $\mathrm{V}_{0}$ by PEG dilution averaged $98.8 \%$ of $\mathrm{V}_{0}$ measured directly with a coefficient of variation of $2.8 \%$. All calculations presented below are based on direct measurement of $V_{0}$. Net flux defined by Eq. 1 also requires a small correction for residual volume in the pouches. Residual volume was measured on three separate occasions for each dog by emptying the pouches after an exhaustive saline wash, instilling a known volume of saline containing $\left[{ }^{14} \mathrm{C}\right] \mathrm{PEG}$, mixing thoroughly by barbotage, and measuring the dilution of ${ }^{14} \mathrm{C}$. Values in all dogs ranged from 0.55 to $2.1 \mathrm{ml}$ and for any given dog did not vary by more than $0.5 \mathrm{ml}$. Therefore each dog's residual volume was assumed to be constant at that dog's average value. This value was multiplied by the change in $\left[\mathrm{Na}^{+}\right]$during the test period, divided by time, and added to the net flux calculated in Eq. 1 . Correction for residual volume represented an increase in the calculated net flux of $\sim 5 \%$. Finally, change in net $\mathrm{Na}^{+}$flux induced by the bile acid solution was calculated by subtracting the mean prebile acid solution flux from the postbile acid solution flux. Change in mean net $\mathrm{H}^{+}$flux was calculated in exactly analogous fashion.

Bile acid mass in solutions instilled into and removed from the Heidenhain pouches was determined by an automated procedure based on Talalay's enzymatic assay (15) as described in previous publications (16). Mean uptake rate of bile acid by the pouches was calculated according to Eq. 1 substituting concentrations of bile acid for concentrations of $\mathrm{Na}^{+}$. Taurodehydrocholate can not be measured by this enzymatic method. Uptake of this bile acid was determined using $\left[{ }^{14} \mathrm{C}\right]-$ taurodehydrocholate of known specific activity. Scintillation counting in these experiments was performed in a 10:1 mixture of Aquasol (New England Nuclear) using a Packard Tricarb model 3330 (Packard Instrument Co., Inc., Downers Grove, Ill.)

Phospholipid and cholesterol efflux from the Heidenhain pouches was determined by performing a $\mathrm{CHCl}_{3} / \mathrm{MeOH}_{\text {ex- }}$ traction on a $7.5 \mathrm{~cm}^{3}$ aliquot of the bile acid solution recovered from the pouches. The $\mathrm{CHCl}_{3}$ phase was assayed for cholesterol by a gas-liquid chromatography procedure and for total phospholipid by standard techniques, both described (16). Efflux was calculated according to the following equation:

$$
\text { Lipid efflux }=\frac{[\mathrm{L}] \mathrm{V}}{\mathrm{t}},
$$

where [L] is the concentration of lipid, $\mathrm{V}$ is the volume of bile acid solution retrieved from the pouch, and $t$ is time the solution was in the pouch. Again, in early experiments $\mathrm{V}$ for these calculations (and for the bile acid absorption calculations) was determined both by direct measurement and by dilution of $\left[{ }^{3} \mathrm{H}\right] \mathrm{PEG}$ in the instilled solution. In these initial studies $\mathrm{V}$ determined by $\left[{ }^{3} \mathrm{H}\right]$ PEG dilution averaged $106.2 \pm 4.1 \%$ of $\mathrm{V}$ measured directly. This appeared to represent a slight over-estimate of volume by $\left[{ }^{3} \mathrm{H}\right] \mathrm{PEG}$ dilution resulting from a tritiated contaminant being absorbed from the pouches. Therefore, all calculations presented below are based on direct measurement of V. Finally, a correction for residual volume was applied as described above for calculations of $\left[\mathrm{Na}^{+}\right]$flux.

Some of the $\mathrm{CHCl}_{3}$ extracts were analyzed for individual phospholipids by two-dimensional thin-layer chromatography 
on silica gel $\mathrm{G}$. Plates were developed in one direction with $\mathrm{CHCl}_{3} / \mathrm{MeOH} / \mathrm{H}_{2} \mathrm{O}, 65: 25: 5$ and in the perpendicular direction with butanol/ $\mathrm{HAc} / \mathrm{H}_{2} \mathrm{O}, 60: 20: 20$. Individual lipid spots were identified with $I_{2}$ vapor with comparison to reference standards. Spots were scraped directly into digestion flasks for determination of phospholipid. This procedure provided $>85 \%$ recovery as judged by analysis of phospholipid standards.

Analysis of gastric mucosal phospholipids and cholesterol was performed in identical fashion. Samples of mucosa were obtained by scraping with a scalpel blade from specimens removed just before killing. Part of the mucosal scraping was taken for histology. The remaining material was frozen in liquid nitrogen and ground to a fine powder. Weighed samples of this powder were extracted with $\mathrm{CHCl}_{3} / \mathrm{MeOH}$ for lipid analysis.

\section{RESULTS}

The effect of a 40-min exposure of Heidenhain pouches to $0.05 \mathrm{M} \mathrm{PO}_{4}-0.10 \mathrm{M} \mathrm{NaCl}(\mathrm{pH} 7)$, used as a vehicle for bile acids in all subsequent studies, is shown in Fig. 1. This buffer induced small changes in net forwarddiffusion of $\mathrm{Na}^{+}(2.8 \pm 0.6 \mu \mathrm{eq} / \mathrm{min})$ and back-diffusion of $\mathrm{H}^{+}(0.7 \pm 1.0 \mu \mathrm{eq} / \mathrm{min}) .^{2}$ Addition of a mixture of six conjugated bile acids simulating the proportions in human bile (see Methods for composition) to a concentration of $10 \mathrm{mM}$ increased $\mathrm{Na}^{+}$forward-diffusion almost sevenfold to $18.3 \pm 3.2 \mu \mathrm{eq} / \mathrm{min}(P<0.001)$ and increased $\mathrm{H}^{+}$back-diffusion about 15 -fold to $10.6 \pm 3.3$ $\mu \mathrm{eq} / \mathrm{min}(P<0.01)$. As shown in Fig. 1 , these values

${ }^{2}$ All net fluxes $\left(\mathrm{Na}^{+}, \mathrm{H}^{+}\right.$, bile acid, phospholipid, and cholesterol) reported in this study are average values obtained by dividing total net flux in any given experimental period by number of minutes in that period.

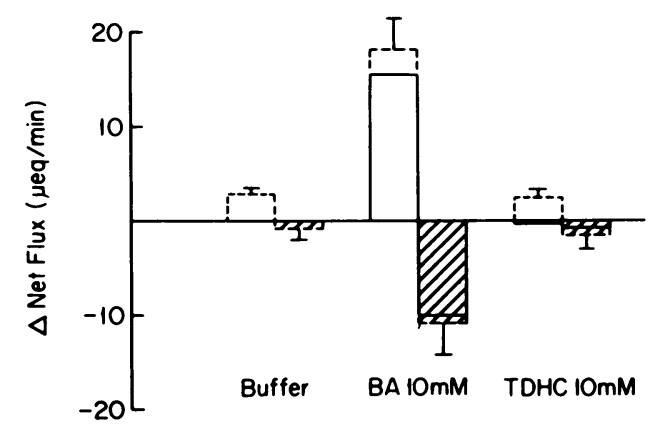

Figure l Change in net flux of $\mathrm{Na}^{+}$(open bars) and $\mathrm{H}^{+}$ (cross-hatched bars) after a 40-minute exposure to $0.10 \mathrm{M}$ NaCl-0.05 $\mathrm{M} \mathrm{PO}_{4}$ buffer, a $10 \mathrm{mM}$ mixture of six conjugated bile acids (BA) in that buffer, and $10 \mathrm{mM}$ taurodehydrocholate (TDHC) in buffer. Positive change indicates net movement into the Heidenhain pouch. Values obtained in the BA and TDHC studies were corrected for small increments in $\mathrm{Na}^{+}$ and $\mathrm{H}^{+}$net flux observed after exposure to buffer alone as indicated by the dotted portion of the bars. All data presented subsequently have been corrected in similar fashion. The $10 \mathrm{mM}$ BA solution significantly increased both $\mathrm{Na}^{+}$forward-diffusion $(P<0.001)$ and $\mathrm{H}^{+}$back-diffusion relative to the buffer $(P<0.01)$. TDHC had no such effect. were corrected for the increment in net $\mathrm{Na}^{+}$and $\mathrm{H}^{+}$ flux attributable to the phosphate-buffered saline. This correction reduced the value for change in net $\mathrm{Na}^{+}$ flux to $15.5 \mu \mathrm{eq} / \mathrm{min}$ and the value for change in net $\mathrm{H}^{+}$flux to $9.9 \mu \mathrm{e}(\mathrm{g} / \mathrm{min}$. A similar correction was applied in the calculation of all data reported below. That change in net $\mathrm{Na}^{+}$forward-diffusion is not necessarily equal to change in net $\mathrm{H}^{+}$back-diffusion has been observed by others (17) and suggests something other than simply one for one exchange of these two cations.

Also shown in Fig. 1 is the result of a 40-min exposure of the pouches to a $10 \mathrm{mM}$ solution of taurodehydrocholate. This bile salt, which does not form micelles (18), had no effect on net $\mathrm{Na}^{+}$flux $(-0.3 \pm 0.8 \mu \mathrm{eq} / \mathrm{min})$ or net $\mathrm{H}^{+}$flux $(-0.7 \pm 1.4 \mu \mathrm{eq} / \mathrm{min})$.

Effluxes of phospholipid and cholesterol from gastric mucosa into solutions in the pouch lumena are shown in Fig. 2. Phosphate buffer alone was associated with an efflux rate for phospholipid of $13.2 \pm 2.7 \mathrm{nmol} / \mathrm{min}$ and for cholesterol of $11.7 \pm 3.8 \mathrm{nmol} / \mathrm{min}$. The $10 \mathrm{mM}$ mixture of bile acids increased phospholipid efflux fourfold to $54.8 \pm 2.8 \mathrm{nmol} / \mathrm{min}$ and increased cholesterol efflux threefold to $36.3 \pm 3.2 \mathrm{nmol} / \mathrm{min}(P<0.001$

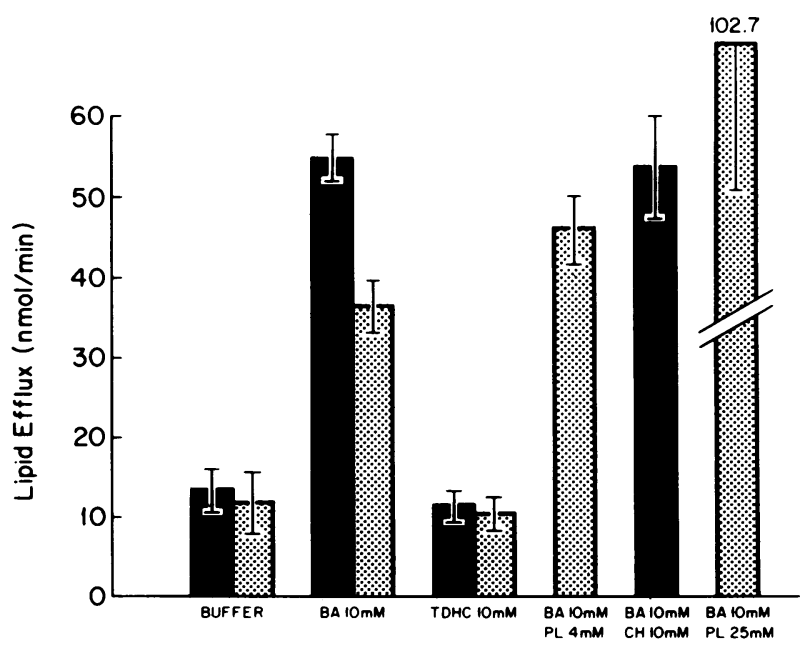

FIGURE 2 Efflux of phospholipid (solid bars) and cholesterol (stippled bars) from the mucosa of Heidenhain pouches during a 40-min exposure to the solutions indicated. The $10 \mathrm{mM}$ bile salt (BA) solution increased efflux of phospholipid fourfold and cholesterol threefold as compared to buffer alone ( $P$ $<0.001$ for both lipids). A $10 \mathrm{mM}$ solution of taurodehydrocholate (TDHC) did not increase efflux of either lipid over values observed for buffer alone. Increased efflux of cholesterol relative to buffer persisted after addition of either $4 \mathrm{mM}$ lecithin (PL) $(P<0.001)$ or saturation with $25 \mathrm{mM}$ PL $(P$ $<0.001)$. Increased efflux of phospholipid relative to buffer persisted after saturation with $10 \mathrm{mM}(\mathrm{CH})(P<0.001)$. This persistent increased efflux of phospholipid or cholesterol in the presence of saturation amounts of the other lipid provides an explanation for the continued capacity of these solutions to disrupt the gastric mucosal barrier since saturation with both lipids completely prevented such disruption (Fig. 3). 
compared to buffer values for both). Lipid effluxes into $10 \mathrm{mM}$ taurodehydrocholate were virtually identical to those into phosphate buffer, $11.3 \pm 1.7 \mathrm{nmol} / \mathrm{min}$ for phospholipid and $10.4 \pm 2.0 \mathrm{nmol} / \mathrm{min}$ for cholesterol.

Analysis of individual phospholipids eluted into the $10 \mathrm{mM}$ bile acid solution is presented in Table I. Lecithin constituted $52.7 \%$ of these phospholipids and its degradation product, lysolecithin, constituted another $9.6 \%$. The remaining eluted phospholipid was largely phosphatidyl ethanolamine $(19.7 \%)$ with smaller amounts of phosphatidyl serine, phosphatidyl inositol, and sphingomyelin. Comparison of these percentages to those of phospholipids extracted from gastric mucosa (Table I) suggests that a disproportionate amount of mucosal lecithin was eluted by the bile acid solution since only $43.2 \%$ of mucosal phospholipid was lecithin and none was lysolecithin.

Attempts to block bile acid-induced changes in $\mathrm{Na}^{+}$ and $\mathrm{H}^{+}$net fluxes by addition of phospholipid and cholesterol are shown in Fig. 3. Saturation of the $10 \mathrm{mM}$ mixture of bile acids with $25 \mathrm{mM}$ lecithin did not prevent alteration of $\mathrm{Na}^{+}$forward-diffusion (11.8 \pm 2.1 $\mu \mathrm{eq} / \mathrm{min})$ or $\mathrm{H}^{+}$back-diffusion $(7.6 \pm 2.3 \mu \mathrm{eq} / \mathrm{min})$. Saturation of the $10 \mathrm{mM}$ bile acid mixture with cholesterol also was ineffective in preventing changes in $\mathrm{Na}^{+}$ forward-diffusion $(17.4 \pm 2.6)$ and $\mathrm{H}^{+}$back-diffusion $(13.0 \pm 1.9)$. However, saturation of the bile acid mixture with both lecithin and cholesterol completely prevented induction of $\mathrm{Na}^{+}$forward-diffusion $(-1.2 \pm 0.9)$ and $\mathrm{H}^{+}$back-diffusion $(0.6 \pm 1.8 \mu \mathrm{eq} / \mathrm{min})$. An explanation for the continued injurious potential of bile acid solutions saturated with either lecithin or cholesterol alone may be found in Fig. 2. These data show continued efflux of mucosal cholesterol $(102.7 \pm 18.7 \mathrm{nmol} /$ $\mathrm{min}$ ) into the solution saturated with lecithin and continued efflux of mucosal phospholipid $(53.5 \pm 6.4 \mathrm{nmol} /$ $\mathrm{min}$ ) into the solution saturated with cholesterol.

TABLE I

Characterization of Phospholipids Extracted from Gastric Mucosal Scrapings and from $10 \mathrm{mM}$ Bile Salt Solutions Removed from Heidenhain Pouches after a 40-min Exposure

\begin{tabular}{lcc}
\hline & Gastric mucosa & Bile salt solution \\
\hline & & $\%$ \\
Lecithin & $43.2 \pm 1.6$ & $52.7 \pm 0.8$ \\
Lysolecithin & 0 & $9.6 \pm 1.2$ \\
$\begin{array}{l}\text { Phosphatidyl } \\
\text { ethanolamine }\end{array}$ & $30.4 \pm 1.1$ & $19.7 \pm 2.6$ \\
Phosphatidyl serine & & \\
$\quad$ and inositol & $9.0 \pm 1.3$ & $9.0 \pm 2.3$ \\
Sphingomyelin & $15.2 \pm 0.6$ & $9.1 \pm 1.0$ \\
Cardiolipin & $2.1 \pm 1.3$ & 0 \\
\hline
\end{tabular}

Mean $\pm \mathrm{SEM}, n=4$ in both cases.

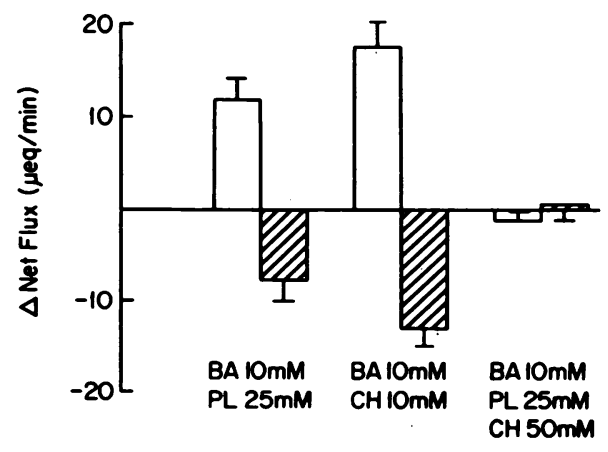

Figure 3 Change in net flux of $\mathrm{Na}^{+}$(open bars) and $\mathrm{H}^{+}$(crosshatched bars) induced by the $10 \mathrm{mM}$ bile acid (BA) solution saturated with lecithin (PL), cholesterol $(\mathrm{CH})$, or both. All three solutions were saturated after sonication as judged by the presence of milky turbidity. Neither saturation with PL alone or $\mathrm{CH}$ alone prevented disruption of the gastric mucosal barrier, presumably because of persistently increased efflux of the missing lipid from the Heidenhain pouch mucosa (Fig. 2). Saturation with both lipids completely prevented net forward-diffusion of $\mathrm{Na}^{+}$and back-diffusion of $\mathrm{H}^{+}$induced by $10 \mathrm{mM}$ BA alone (Fig. 1).

Bile acid was absorbed by Heidenhain pouches from the $10 \mathrm{mM}$ bile acid mixture at $752 \pm 86 \mathrm{nmol} / \mathrm{min}$ (Fig. 4). Addition of subsaturation amounts of lecithin to this solution reduced bile acid absorption to $252 \pm 57$ $\mathrm{nmol} / \mathrm{min}(P<0.001)$. Despite this threefold reduction in bile acid absorption, this solution induced net $\mathrm{Na}^{+}$ forward-diffusion of $14.1 \pm 3.4 \mu \mathrm{eq} / \mathrm{min}$ and net $\mathrm{H}^{+}$ back-diffusion of $15.6 \pm 3.5 \mu \mathrm{eq} / \mathrm{min}$, values as high or higher than those observed for $10 \mathrm{mM}$ bile acid alone (Fig. 1). Taurodehydrocholate was absorbed by the pouches to an intermediate extent $(467 \pm 116 \mathrm{nmol} / \mathrm{min}$, Fig. 4) despite its lack of effect on net $\mathrm{Na}^{+}$and $\mathrm{H}^{+}$ fluxes (Fig. 1). These data provide two separate instances of dissociation between bile acid uptake by the gastric mucosa and disruption of the gastric mucosal barrier.

\section{DISCUSSION}

In the present study three lines of evidence implicate micellar dissolution of mucosal lipids as the mechanism by which bile salts disrupt the gastric mucosal barrier. First a mixture of conjugated bile salts, shown to increase $\mathrm{H}^{+}$back-diffusion and $\mathrm{Na}^{+}$forward-diffusion, increased efflux of phospholipid and cholesterol out of the gastric mucosa (Fig. 2). Such efflux of phospholipid has also been reported by Thomas et al. (19) during exposure of rat gastric mucosa to solutions of sodium taurocholate. Second, the nonmicellar bile salt, taurodehydrocholate, did not alter net flux of either $\mathrm{Na}^{+}$ or $\mathrm{H}^{+}$(Fig. 1) and did not increase either phospholipid or cholesterol efflux from the mucosa (Fig. 2). Finally, saturation of the bile salt mixture with lecithin and cholesterol completely prevented changes in net flux of 


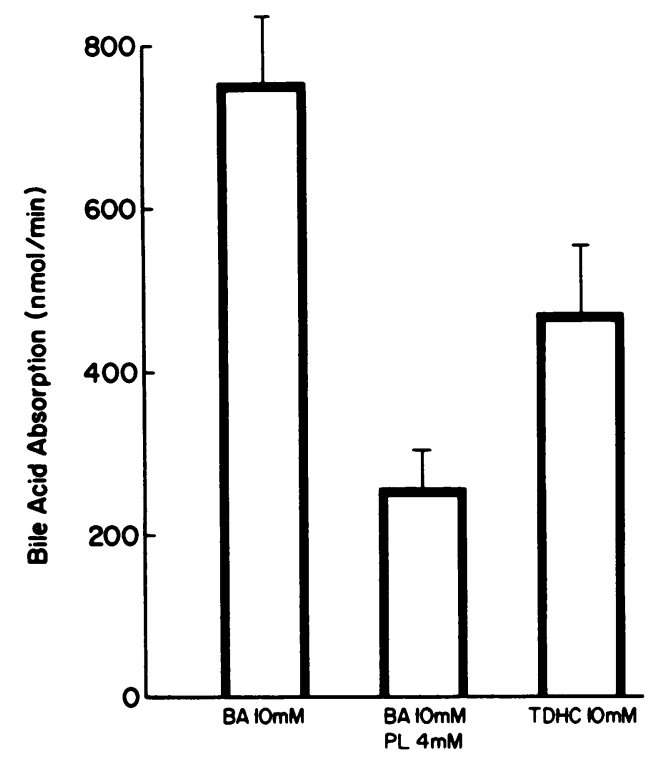

Figure 4 Bile acid uptake by Heidenhain pouches during a 40-min test period. Addition of subsaturation amounts of lecithin (PL; $4 \mathrm{mM}$ ) reduced absorption from the $10 \mathrm{mM}$ bile acid solution (BA) threefold $(P<0.001)$. Despite this reduced absorption, the BA-PL mixture induced net forward-diffusion of $\mathrm{Na}^{+}$at $14.1 \pm 3.4 \mu \mathrm{eq} / \mathrm{min}$ and net back-diffusion of $\mathrm{H}^{+}$at 15.6 $\pm 3.5 \mu \mathrm{eq} / \mathrm{min}$ suggesting that changes in $\mathrm{Na}^{+}$and $\mathrm{H}^{+}$ fluxes are not mediated by mucosal uptake of BA. This conclusion was further strengthened by the observation that taurodehydrocholate (TDHC) absorption, measured with the use of tracer $\left[{ }^{14} \mathrm{C}\right] \mathrm{TDHC}$, was as high or higher than bile acid uptake from the solution containing $4 \mathrm{mM}$ PL despite the lack of effect of TDHC on net flux of $\mathrm{Na}^{+}$and $\mathrm{H}^{+}$(Fig. 1).

$\mathrm{Na}^{+}$and $\mathrm{H}^{+}$induced by bile salt alone (Fig. 3). This same bile salt mixture saturated with either phospholipid or cholesterol continued to promote efflux of the other lipid from the mucosa (Fig. 2) and continued to induce net forward-diffusion of $\mathrm{Na}^{+}$and back-diffusion of $\mathrm{H}^{+}$(Fig. 3). These observations provide a firm indication that bile salts disrupt the gastric mucosal barrier by dissolving mucosal lipids and suggest that dissolution of either phospholipid or cholesterol is sufficient to induce this disruption.

If disruption of the gastric mucosal barrier is a detergent effect of intralumenal bile salt, such disruption should not occur below the critical micellar concentration (CMC) of bile salt mixed micelles. Unfortunately, much of the literature relevant to this issue is conflicting and incomplete. Taurocholate, the single bile salt most extensively studied, has been reported to have threshold concentrations for gastric mucosal injury of 1 , 2,10 , and $15 \mathrm{mM}(5-7,20)$. The first three of these estimates were obtained in acid solutions, for which we can find no published measurements of the CMC. The estimate of $15 \mathrm{mM}$ was obtained in neutral solution where the CMC of taurocholate is $\sim 5 \mathrm{mM}(21)$. When compared in the same investigations, deoxycholates consistently produce gastric mucosal injury at lower concentrations than do cholates $(5,20)$. This difference in potency is compatible with micelle-mediated injury since deoxycholates have lower CMC than cholates (21). Finally we have previously reported that the same mixture of six conjugated bile salts employed in the present study must be concentrated above $\sim 2.5 \mathrm{mM}$ before alteration of gastric mucosal flux of $\mathrm{Na}^{+}$or $\mathrm{H}^{+}$ occurs (14). We have also reported that CMC of this same mixture of bile salts in the presence of lecithin to be $0.5 \mathrm{mM}(22)$. These findings further strengthen the hypothesis that bile salts disrupt the gastric mucosal barrier by dissolving mucosal lipids.

The studies of Forte et al. (3) provide an anatomical correlate to our findings. Using electron-microscopic techniques they found that gastric mucosal damage after a 30-min exposure to deoxycholate was largely limited to the apical mucosal surface, as would be expected if intralumenal bile salt were responsible for the damage. These changes ranged from ruffling and pitting of the epithelial surface to denudation of apical epithelium. The authors concluded that the apical plasma membrane may be the primary anatomical gastric mucosal barrier. Since phospholipids and cholesterol are essential structural elements of such membranes, this conclusion, and the histological changes leading to it, are consistent with the hypothesis that bile salts injure the gastric mucosa by dissolving these membrane lipids.

The alternative to an intralumenal mechanism of injury is that bile salt enters the mucosal cells causing metabolic disruption manifested by changes in net fluxes of $\mathrm{Na}^{+}$or $\mathrm{H}^{+}$. Our data and those of Davenport (11) certainly demonstrate that the gastric mucosa can absorb bile salt. However, two observations in the present study directly challenge the importance of this uptake in disruption of the gastric mucosal barrier. First, addition of subsaturation amounts of lecithin to the 10 $\mathrm{mM}$ bile salt mixture reduced mucosal uptake of bile salt threefold (Fig. 4), but did not diminish bile salt effects on $\mathrm{Na}^{+}$and $\mathrm{H}^{+}$fluxes (Results). Second, taurodehydrocholate, which did not disrupt the gastric mucosal barrier (Fig. 1), was absorbed by the gastric mucosa faster than was bile salt from the solution containing subsaturation amounts of lecithin (Fig. 4). These observations strongly suggest that disruption of the gastric mucosal barrier is not an effect of intramucosal bile salt.

Although dissolution of mucosal lipids appears to cause disruption of the gastric mucosal barrier, such dissolution may not be the only mechanism by which bile salt can injure the gastric mucosa. In vitro studies of isolated bullfrog gastric mucosa have shown that exposure of the serosal surface of this preparation to bile salt causes definite changes in both histological and electrical characteristics of the tissue $(3,5)$. These changes, which differ from those after exposure of the mucosal surface to bile salt, could be a result of entry of bile salt into the mucosa or dissolution of lipids on the 
serosal surface of the tissue. Favoring the possibility that intramucosal bile salt causes some injury in this preparation is the observation that dehydrocholate, placed on the mucosal surface, causes changes in tissue electrical properties and $\mathrm{H}^{+}$secretion resembling those caused by mucosal exposure to taurocholate (5). These changes are not likely to be a result of dissolution of mucosal lipids because dehydrocholate does not form micelles (18). This in vitro system, lacking the defense mechanisms and regenerative capacities of in vivo tissue, may be a particularly sensitive barometer for injurious effects of bile salt. The importance of such effects in vivo, particularly under conditions of compromised tissue defenses, deserves further investigation.

This study stemmed from investigations into the pathogenesis of reflux gastritis after antrectomy and vagotomy (14). Because most patients with that condition have an intragastric $\mathrm{pH}>5$, we elected to perform our experiments at neutral, rather than acidic, $\mathrm{pH}$. These experimental conditions also facilitated the study of a physiologic mixture of conjugated bile salts, most of which would precipitate at a $\mathrm{pH}<4(21)$. Assuming that under these conditions bile salts affect canine and human stomach similarly, our results suggest that the contribution of bile salts to the pathogenesis of reflux gastritis is mediated, at least in part, through dissolution of gastric mucosal phospholipid and cholesterol.

An additional advantage of using neutral $\mathrm{pH}$ was that our results could be interpreted in light of physical-chemical characteristics of bile salts. Very few such data have been obtained at acidic $\mathrm{pH}$, although it is known that taurodeoxycholic acid can form micelles at pH 2 (21). One disadvantage of this experimental design is that results obtained at neutral $\mathrm{pH}$ are of uncertain relevance to the pathogenesis of gastric ulcer disease, a condition to which reflux of bile salt is thought to contribute, but in which gastric $\mathrm{pH}$ is often quite acidic $(23,24)$. Confident assessment of the importance of mucosal lipid dissolution in the pathogenesis of gastric ulcer disease will require study of both gastric toxicity and physical-chemical characteristics for bile salts at acid $\mathrm{pH}$.

\section{ACKNOWLEDGMENTS}

Doctors J. A. Vennes and S. E. Silvis graciously provided the time of Mr. Chester E. Sievert, who skillfully constructed the Heidenhain pouches. Valarie Wesley carefully prepared the manuscript.

\section{REFERENCES}

1. Davenport, H. W. 1968. Destruction of the gastric mucosal barrier by detergents and urea. Gastroenterology. 54: $175-181$.

2. Ivey, K. J., L. DenBesten, and J. A. Clifton. 1970. Effect of bile salts on ionic movement across the human gastric mucosa. Gastroenterology. 59: 683-690.

3. Forte, T. M., W. Silen, and J. G. Forte. 1976. Ultrastructural lesions in gastric mucosa exposed to deoxycholate: implications toward the barrier concept. In Gastric Hydrogen Ion Secretion. D. K. Kasbekar, G. Sachs, and W. S. Rehm, editors. Marcel Dekker, Inc., New York. 1-28.

4. Kivilaakso, E., and W. Silen. 1979. Pathogenesis of experimental gastric-mucosal injury. N. Engl. J. Med. 301: $364-369$.

5. Silen, W., and J. G. Forte. 1975. Effects of bile salts on amphibian gastric mucosa. Am. J. Physiol. 228: 637-644.

6. Eastwood, G. L. 1975. Effect of pH on bile salt injury to mouse gastric mucosa. Gastroenterology. 68: 1456-1465.

7. Ritchie, W. P., and K. J. Cherry. 1979. Influence of hydrogen ion concentration on bile acid induced acute gastric mucosal ulcerogenesis. Ann. Surg. 189: 637-642.

8. Hoare, A. M., M. R. B. Keighley, B. Starkey, and J. Alexander-Williams. 1978. Measurement of bile acids in fasting gastric aspirates: an objective test for bile reflux after gastric surgery. Gut. 19: 166-169.

9. Hoare, A. M., A. McLeish, H. Thompson, and J. Alexander-Williams. 1978. Selection of patients for bile diversion surgery: use of bile acid measurement in fasting gastric aspirates. Gut. 19: 163-165.

10. Gadacz, T. R., and G. D. Zuidema. 1978. Bile acid composition in patients with and without symptoms of postoperative reflux gastritis. Am. J. Surg. 135: 48-50.

11. Davenport, H. W. 1967. Absorption of taurocholate- $24-{ }^{14} \mathrm{C}$ through the canine gastric mucosa. Proc. Soc. Exp. Biol. Med. 125: 670-673.

12. Siekevitz, P. 1970. The organization of biologic membranes. N. Engl. J. Med. 283: 1035-1041.

13. Slota, T., and H. V. Ammon. 1979. Cholesterol inhibits the effect of taurodeoxycholate on jejunal water transport in man. Gastroenterology. 76: 1250.

14. Duane, W. C., D. M. Wiegand, and M. L. Gilberstadt. 1980. Intragastric duodenal lipids in the absence of a pyloric sphincter: quantitation, physical state, and injurious potential in the fasting and postprandial states. Gastroenterology. 78: 1480-1487.

15. Talalay, P. 1960. Enzymic analysis of steroid hormones. Methods Biochem. Anal. 8: 119-143, 1960.

16. Duane, W. C., R. L. Ginsberg, and L. J. Bennion. 1976. Effects of fasting on bile acid metabolism and biliary lipid composition in man. J. Lipid Res. 17: 211-219.

17. Chung, R. S. K., M. Field, and W. Silen. 1978. Effects of methylprednisolone on hydrogen ion absorption in the canine stomach. J. Clin. Invest. 62: 262-270.

18. Small, D. M. 1968. Size and structure of bile salt micelles. Advances Chem. 84: 31-52.

19. Thomas, A. J., D. L. Nahrwold, and R. C. Rose. 1972. Detergent action of sodium taurocholate on rat gastric mucosa. Biochim. Biophys. Acta 282: 210-213.

20. Harmon, J. W., T. Doong, and T. R. Gadacz. 1978. Bile acids are not equally damaging to the gastric mucosa. Surgery. 84: 79-86.

21. Small, D. M. 1971. The physical chemistry of cholanic acids. In The Bile Acids. P. P. Nair and D. Kritchevsky, editors. Plenum Publishing Corp., New York. 249-355.

22. Duane, W. C. 1975. The intermicellar bile salt concentration in equilibrium with mixed micelles of human bile. Biochim. Biophys. Acta. 398: 275-286.

23. Rhodes, J., D. E. Barnardo, S. F. Phillips, R. A. Rovelstad, and A. F. Hofmann. 1969. Increased reflux of bile into the stomach in patients with gastric ulcer. Gastroenterology. 57: 241-252.

24. Black, R. B., G. Roberts, and J. Rhodes. 1971. The effects of healing on bile reflux in gastric ulcer. Gut. 12: 552-558. 